\title{
Research of Transformer Intelligent Evaluation and Diagnosis Method Based on DGA
}

\author{
Wang Feng, Bi jiangang, Zhang bowen, Yuan Shuai \\ China Electric Power Research Institute, Haidian District, Beijing, China
}

\begin{abstract}
Oil chromatography analysis is the foundation of transformer fault diagnosis, In this paper, based on knowledge base of the oil chromatographic analysis, an extended research combining the improved three ratio method, BP neural network, and case-based reasoning method for the transformer fault diagnosis was proposed, in the purpose of building a transformer Intelligent Evaluation Diagnosis model, to improve the accuracy of the transformer fault diagnosis, which is of a great significance for practice.
\end{abstract}

\section{Introduction}

With the development of society and economy, energy and environmental issues is becoming increasingly prominent. In order to meet the requirements of a sustainable future, the development and construction of a strong smart grid is an inevitable choice to promote China's economic development.

Safe operation of the power transformer is to ensure a reliable, safety power grid and the necessary conditions for stable operation. The main transformer on-line monitoring of transformer oil chromatogram is analysed to determine the latent fault transformer. Oil chromatographic analysis is one of the most effective methods of early detection and prevention of transformer failures. Because the neural network to outside input sample has a strong ability to identify and classify information processing characteristics of associative memory, making the application of artificial neural networks and fault diagnosis of transformer combined. Therefore, the neural network fault diagnosis method based on chromatographic analysis of transformer oil for transformer fault diagnosis provides a new way.

\section{Transformer fault diagnosis research status}

Power transformer fault, from the development process can be divided into two categories: sudden failure and latent failures. For sudden failure we can use some conservative measures for prevention, existing methods mainly for the purposes of latent failures. Latent failures can be divided into three categories: internal transformer partial discharge, local overheating and transformer insulation aging. Power transformer is closely related to the failure of the transformer condition, history $\log$, and transformer models. Therefore, it is necessary to study the transformer fault, timely and accurate detection of early latent transformer fault detection and maintenance system to develop a reasonable, accurate service, improve the reliability of transformers [1].

Expert System has received a preliminary application, but the main problem is that the "bottleneck" problem of knowledge acquisition cannot effectively solve so many uncertainties that exist in fault diagnosis, these problems greatly affected the accuracy of fault diagnosis. Fuzzy diagnosis method using fuzzy matching principle troubleshooting, there are some false positives, generally rarely used. In a variety of intelligent algorithms, neural network model with good nonlinear approximation capability has been widely adopted, has been well developed in the transformer fault diagnosis [2].

In this paper, the traditional methods and BP intelligent algorithm combined with the introduction of Case-based inference and thought transformer fault diagnosis system, conducted in-depth research.

\section{Establish transformer fault diagnosis model}

The failure mechanism of transformers is often very complex, accompanied by a variety of fault generation, which can be used to characterize and determine the fault type of state amount is often more than one correspondence between the amount of state failure and more complicated. Failure mechanism is the basis for fault diagnosis master, research and state the amount of transformer failure relationship is very necessary. The actual amount of fault diagnosis system using state oil chromatogram, the core ground current, infrared, casing, top oil temperature, moisture. 


\subsection{Transformer condition data quality analysis}

During the first transformer fault diagnosis before the collected data processing and analysis, the main purpose is to:

1) Random noise can be treated through treatment, to improve signal to noise ratio, in order to prevent false positives or false negatives fault made, the key is to improve the anti-jamming measures.

2) In addition to improving the SNR beyond, the need to collect data that can better reflect the information displayed, which can not simply set out the collected raw data, while outside to the inside to do some analysis and processing make it a reliable criterion for transformer fault diagnosis.

Quality analysis of the data included four areas: identification of invalid data; complete analysis; normative analysis; stable consistency analysis.

\subsection{Transformer fault diagnosis process}

Transformer fault diagnosis in two steps: to determine whether the fault and the fault type. In the absence of a transformer failure, want to run the state of the transformer to predict and forecast, after a failure of judgment transformer fault type, location, cause, degree, and maintenance decisions. Specific steps are as follows [3].

\subsubsection{Establish fault sample library}

Failure to create a sample database according to the device type, model, manufacturer, etc. and the accumulation of knowledge and provide training and validation samples for fault diagnosis algorithm.

\subsubsection{Establish the diagnosis algorithm library}

Diagnostic algorithm library provides various types of equipment through the package, all kinds of state amount of diagnostic algorithms. Diagnostic algorithm used in this paper include traditional DGA algorithm, advanced intelligent algorithm with BP algorithm combines Casebased inference.

\subsubsection{Status diagnostics}

Firstly whether the fault diagnosis, determine fault, respectively IEC, BP neural network and Case-based inference three methods to conduct a diagnosis, identified as overheating fault or electrical fault, and then use three methods for secondary diagnosis, determine the specific type of fault.

\subsubsection{Diagnostic results}

To determine what kind of fault to fault location, cause of the failure, malfunction, etc. rating judgment.

\subsection{DGA principle}

In the situation of failure, the transformer oil will be oxygen-decomposed and split-decomposed, and then create the hydrogen and low molecule gases. Unsaturation of the hydrocarbon gas will increase along with the pyrolysis energy density (temperature) growing. Different fault, due to the failure point energy is different at different temperatures and different insulation materials involved in its production of gas situation is different. The use of DGA for device internal fault judgment is based on this principle of gas production characteristics of insulating materials.

Part of the gas dissolved in transformer oil, part floating on the upper (free gas). The valuable gases are $\mathrm{H}_{2} 、 \mathrm{CH}_{4} 、 \mathrm{C}_{2} \mathrm{H}_{6} 、 \mathrm{C}_{2} \mathrm{H}_{2} 、 \mathrm{C}_{2} \mathrm{H}_{4} 、 \mathrm{CO}$ and $\mathrm{CO}_{2}$. Table 1 gives an improved three-ratio method of encoding rules [4].

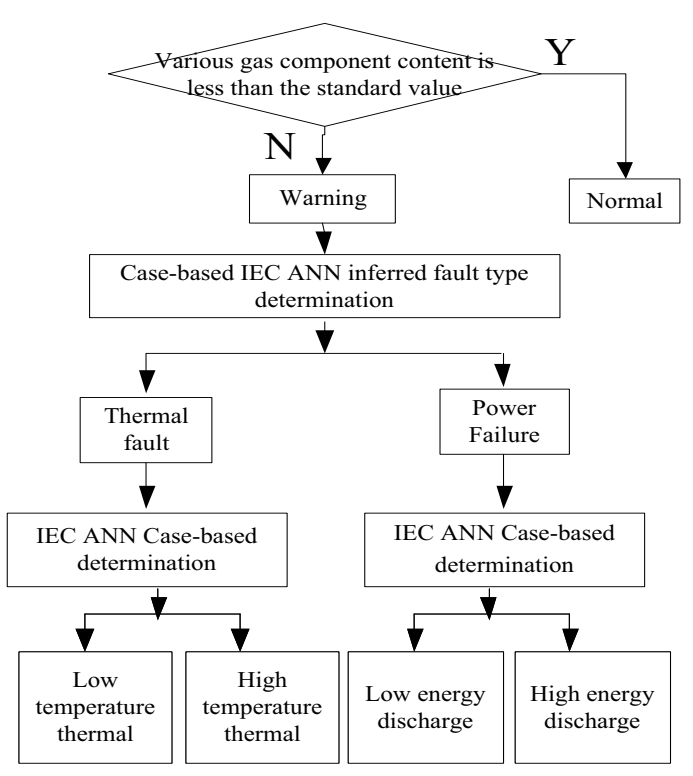

Figure 1.Integrated troubleshooting flowchart transformer

Table 1. Improved three-ratio encoding rules

\begin{tabular}{|c|c|c|c|}
\hline \multirow{2}{*}{ The ratio range } & \multicolumn{3}{|c|}{ Coding ratio range } \\
\cline { 2 - 4 } & $\mathbf{C}_{\mathbf{2}} \mathbf{H}_{\mathbf{2}} / \mathbf{C}_{\mathbf{2}} \mathbf{H}_{\mathbf{4}}$ & $\mathbf{C H}_{\mathbf{4}} / \mathbf{H}_{\mathbf{2}}$ & $\mathbf{C}_{\mathbf{2}} \mathbf{H}_{\mathbf{4}} / \mathbf{C}_{\mathbf{2}} \mathbf{H}_{\mathbf{6}}$ \\
\hline$<0.1$ & 0 & 1 & 0 \\
\hline $0.1 \sim 1$ & 1 & 0 & 0 \\
\hline $1 \sim 3$ & 1 & 2 & 1 \\
\hline$\geqslant 3$ & 2 & 2 & 2 \\
\hline
\end{tabular}

Improved three-ratio method (IEC) is based on the principle of a coding in table 1 to calculate the ratio of the gas, finding the corresponding fault code correlated to the type, you can achieve the purpose of fault diagnosis. The $\mathrm{CO} / \mathrm{CO}_{2}$ ratio needed to be analysed when the solid insulating material was involved in the fault. IEC accuracy rate is about 60 percent, three-ratio method in the early stages of failure is more effective diagnostic methods, But the presence of a fault coding incomplete ratio method, not judge or easy to misjudge, not fully reflect the fault condition and other shortcomings when 
the combined effects of multiple faults. Based on IEC inadequate methods, we propose to combine it with intelligent algorithms [5].

\subsection{Transformer fault diagnosis based on neural network}

BP (Back Propagation) neural network is the earliest typical artificial neural network, that error back propagation algorithm. This paper uses a simple threelayer neural network includes an input layer, an hidden layer and an output layer. Specific configuration shown in Fig. 2:

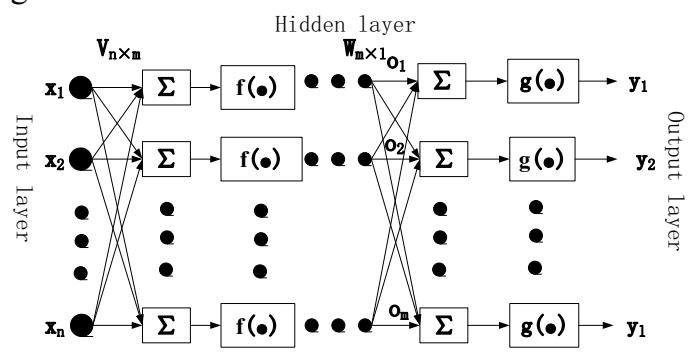

Figure 2. BP Neural network model structure diagram

Among them, the vector $x=\left(x_{1}, \ldots, x_{n}\right)^{T}$ 、 $o=\left(o_{1}, \ldots, o_{m}\right)^{T} 、 \quad y=\left(y_{1}, \ldots, y_{l}\right)^{T} 、 \quad d=\left(d_{1}, \ldots, d_{l}\right)^{T}$ 、 $v=\left(v_{1}, \ldots, v_{m}\right)^{T}$ and ${ }_{w}=\left({ }_{w 1}, \cdots, w_{m}\right)^{T}$ respectively, the input vector (the content of each gas), hidden layer output vector, output vector (equipment failure type), the desired output power weight vector between the input layer and the hidden layer and the hidden layer and output layer between value vector [6-7].

We have established a three-layer BP neural network, set the input layer of the network are $\mathrm{H}_{2} 、 \mathrm{CH}_{4} 、 \mathrm{C}_{2} \mathrm{H}_{6}$ 、 $\mathrm{C}_{2} \mathrm{H}_{2} 、 \mathrm{C}_{2} \mathrm{H}_{4}$ five gas concentration, therefore, the number of nodes in the input layer is 5.Output layer are low energy discharge, high energy discharge, low heat, high temperature overheating, so the output node number is 4 , the output of the corresponding type of fault output is 1 , and the rest is zero.Hidden layer nodes generally use trial and error to determine, $m=2 n+1, n$ is the number of input layer nodes.Through experiments, we finalized a network of hidden nodes $\mathrm{m}$ is 10 , the error is relatively small networks. Fig. 3 shows the hidden layer node training error for different values of the network.

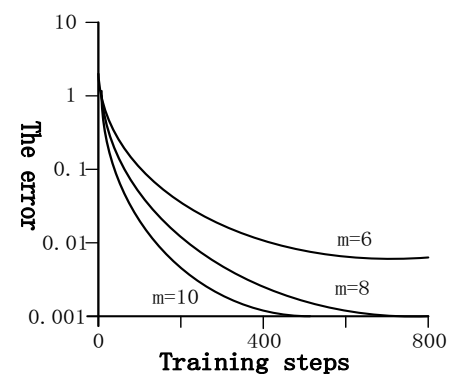

Figure 3. Hidden layer neurons error performance curve

In this paper, the excitation function is sigmoid function, network structure is $5 \times 10 \times 4$.Establishment of the system of five third-order nonlinear dynamic input four output model, shown in Figure 4.The connection weights of BP network of value $v_{i j}, w_{j k}$ and threshold $\theta_{j}$ are random value within $[-1,1]$, The expected error is set to 0.001 , learning rate $\eta$ is 0.01 , Maximum number of training step is 1000 .

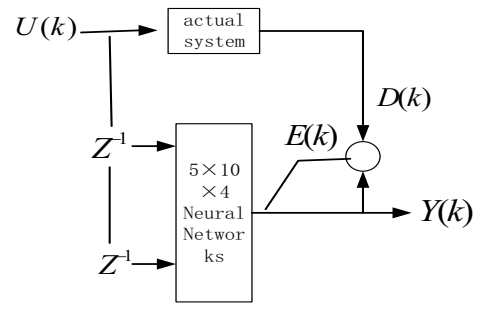

Figure 4. BP nonlinear dynamic model of neural networks

According to the network structure we have established a flow chart of BP neural network algorithm, can be seen from the calculation process flow diagram of the network.

a. Initialize weights and thresholds of the network, set between $[-1,1]$;

b. Training set to a given network, select the fault sample as the network training sample;

c. Layers obtained weights and thresholds, according to the weights and thresholds dressing formula to find the smallest error to make the network weights and thresholds;

d. Strike overall error, the error value calculated according to the formula error model;

e. Whether the termination condition; judgments based on the network settings to achieve maximum error of 0.001 or training times 1000 ;

f. If you meet the requirements to stop the train, otherwise go to step c to continue training.

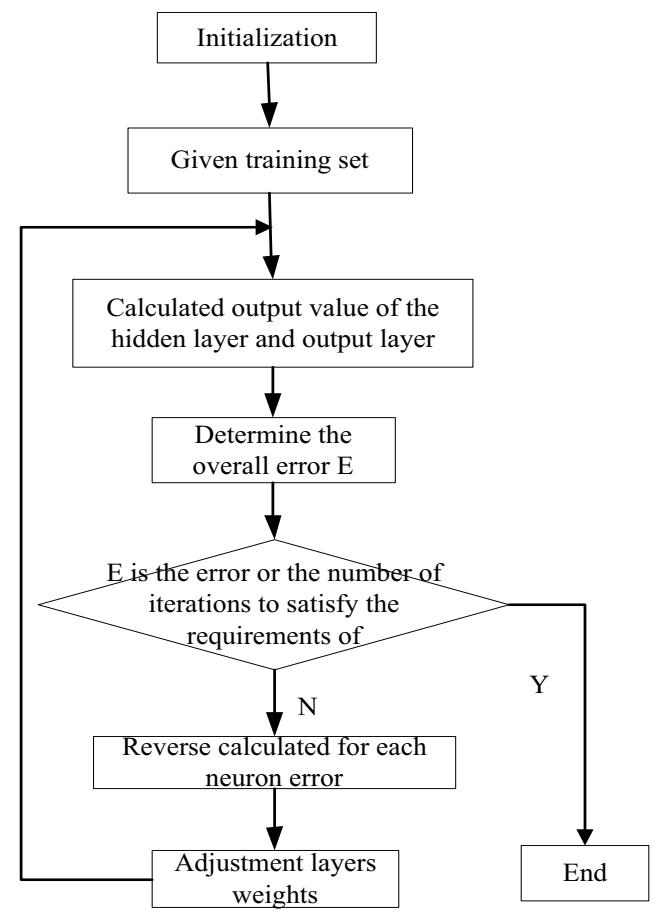

Figure 5. BP neural network algorithm flowchart 


\subsection{Transformer fault diagnosis based on case- based inference}

Case-based analysis for the comparative analysis of similar equipment failure cases, infer accidents, breakdowns and corresponding treatment measures that may occur, which for transformer fault predictive analysis is very helpful.

Case-based analysis of a single point for the analysis of whether there is currently a fault, such as a recent one period of chromatographic data, the data repository with a typical case of an accident or malfunction of some equipment before fairly consistent, then it should be the police immediately, and fault type and treatment measures equipment failure once displayed to the user, in order to adopt the appropriate measures.

Multi-point case-based reasoning was used for analysis of fault thresholds. Consistent with a set of data trends and Case-based devices in a typical case library trends, then the device is currently in good health should also inform the user of the situation, and timely analysis of the two sets of data, propose appropriate implementation of countermeasures. Case-based multipoint analysis than just using a mathematical model to be more accurate and simple, it is a way of reasoning based on historical data.

Change of state of the transformer is nonlinear, especially for off-line data acquisition, affected long interval, the big objective factors such as changes in the environment, and cannot find a proper application of mathematical models only. Case-based analysis can just solve nonlinear prediction problem, but it is more difficult to obtain a sample of the data [8-9].

You can build a transformer fault samples Case-based library management system or through the production of electrical equipment on-line monitoring system. Taking of transformer fault samples have been collected, stored on your computer, we need to be divided into a few simple search space, thereby reducing the load on your computer to improve retrieval efficiency. Specific classification as shown below:

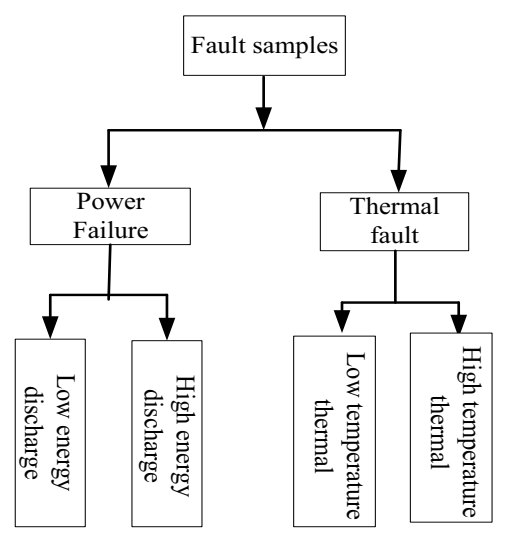

Figure 6. Case-based transformer fault diagnosis based on principles deduced

Selected according to the characteristics of the fault of the different features space retrieval, using the principles of fuzzy matching to find space where the sample, then the sample accurately find space located closest to the sample according to some examples of mathematical algorithms to find the type of fault samples [10].

\section{Result Analysis}

Transformer fault diagnosis and analysis of aspects, with the above methods, the introduction of the failure mechanism and diagnostic reasoning technology to form a comprehensive fault diagnosis method based on artificial neural networks.

DGA using neural networks and transformer fault diagnosis method based on Case-based inference test. Take the results of the test data based on condition monitoring, which includes low energy discharge, high energy discharge, low heat, high temperature overheat four fault types. Gas chromatographic analysis of the oil content of the individual components, the analysis results as input of neural network, trained neural network, a stable neural network model.

In terms of the type of fault diagnosis and analysis of substation equipment, with the diagnostic method of Fig. 1 , the introduction of the failure mechanism and diagnostic reasoning technology to form a comprehensive fault diagnosis method based on artificial neural networks and Case-Based Reasoning transformer.

Table 2. Gas content of each component.

\begin{tabular}{|c|c|c|c|c|c|}
\hline Groups & H2 & CH4 & $\mathrm{C} 2 \mathrm{H} 4$ & С2H6 & $\mathrm{C} 2 \mathrm{H} 2$ \\
\hline 1 & 698.5 & 65.1 & 11.59 & 2.16 & 0 \\
\hline 2 & 4.79 & 11.12 & 3.09 & 27.74 & 0.51 \\
\hline 3 & 33.66 & 2.97 & 27.72 & 33.16 & 2.47 \\
\hline 4 & 42.01 & 33.61 & 8.96 & 14.84 & 0.56 \\
\hline 5 & 16.7 & 16.53 & 57.37 & 6.87 & 2.47 \\
\hline 6 & 16.1 & 24.00 & 48.90 & 10.13 & 0.81 \\
\hline 7 & 84.33 & 8.05 & 0.38 & 7.22 & 0 \\
\hline 8 & 181 & 10.81 & 1 & 0 & 0 \\
\hline 9 & 17.01 & 13.75 & 39.5 & 3.06 & 26.59 \\
\hline 10 & 62.30 & 11.19 & 10.01 & 1.85 & 14.63 \\
\hline 11 & 14 & 5 & 1 & 6 & 5 \\
\hline 12 & 324 & 345 & 748 & 99.6 & 177 \\
\hline 13 & 33.56 & 33.57 & 23.49 & 9.22 & 0.15 \\
\hline 14 & 30.11 & 39.03 & 26.13 & 4.55 & 0.15 \\
\hline 15 & 0.98 & 43.83 & 28.38 & 26.79 & 0 \\
\hline
\end{tabular}

According to the models and methods, selected 15 groups of oil-immersed transformer DGA abnormal conditions were compared to verify the correctness of the algorithm: 
The above table, the question mark is an error of judgment or Missing items, analyze the accuracy of the algorithms for three-ratio method is $66.7 \%$, neural network is $73.3 \%$,integrated algorithm is $80 \%$, which, combined with a comprehensive three-ratio method algorithm, Case-based neural network algorithms and knowledge base, and therefore its high diagnostic accuracy.

Various types of methods for the analysis of the results, the following conclusions:

Table 3. Diagnostic results.

\begin{tabular}{|c|c|c|c|c|}
\hline Groups & Fault type & IEC & BP & $\begin{array}{c}\text { Combined } \\
\text { method }\end{array}$ \\
\hline 1 & $\begin{array}{c}\text { Partial } \\
\text { Discharge }\end{array}$ & $\begin{array}{c}\text { Local low } \\
\text { energy } \\
\text { density and } \\
\text { discharge }\end{array}$ & $\begin{array}{c}\text { Partial } \\
\text { discharge or } \\
\text { moisture }\end{array}$ & $\begin{array}{c}\text { Partial } \\
\text { discharge or } \\
\text { moisture }\end{array}$ \\
\hline 2 & $\begin{array}{c}\text { High } \\
\text { temperature } \\
\text { thermal }\end{array}$ & $\begin{array}{l}\text { Higher than } \\
\text { the range of } \\
700{ }^{\circ} \mathrm{C} \\
\text { thermal fault }\end{array}$ & $?$ & $\begin{array}{c}\text { Partial } \\
\text { discharge or } \\
\text { moisture }\end{array}$ \\
\hline 3 & $\begin{array}{c}\text { Low } \\
\text { temperature } \\
\text { thermal }\end{array}$ & $\begin{array}{c}150{ }^{\circ} \mathrm{C} \text { lower } \\
\text { than the } \\
\text { thermal } \\
\text { breakdown } \\
\text { of }\end{array}$ & $\begin{array}{c}\text { Low } \\
\text { temperature } \\
\text { thermal }\end{array}$ & $\begin{array}{c}\text { High energy } \\
\text { discharge / } \\
\text { high } \\
\text { temperature } \\
\text { overheating }\end{array}$ \\
\hline 4 & $\begin{array}{c}\text { Low } \\
\text { temperature } \\
\text { thermal }\end{array}$ & $\begin{array}{c}\text { General } \\
\text { overheated } \\
\text { wires }\end{array}$ & \begin{tabular}{|c|} 
Low \\
temperature \\
thermal
\end{tabular} & $\begin{array}{c}\text { Low } \\
\text { temperature } \\
\text { thermal }\end{array}$ \\
\hline 5 & $\begin{array}{c}\text { High } \\
\text { temperature } \\
\text { thermal }\end{array}$ & $?$ & $\begin{array}{c}\text { High } \\
\text { temperature } \\
\text { thermal }\end{array}$ & $\begin{array}{c}\text { High energy } \\
\text { discharge / } \\
\text { high } \\
\text { temperature } \\
\text { overheating }\end{array}$ \\
\hline 6 & $\begin{array}{c}\text { High } \\
\text { temperature } \\
\text { thermal } \\
\end{array}$ & $\begin{array}{c}\text { High } \\
\text { temperature } \\
\text { thermal }\end{array}$ & $\begin{array}{c}\text { High } \\
\text { temperature } \\
\text { thermal }\end{array}$ & $\begin{array}{c}\text { High } \\
\text { temperature } \\
\text { thermal }\end{array}$ \\
\hline 7 & $\begin{array}{c}\text { Low energy } \\
\text { discharge }\end{array}$ & $?$ & $\begin{array}{l}\text { Low energy } \\
\text { discharge }\end{array}$ & $\begin{array}{c}\text { Partial } \\
\text { discharge or } \\
\text { moisture }\end{array}$ \\
\hline 8 & $\begin{array}{c}\text { Partial } \\
\text { Discharge }\end{array}$ & $\begin{array}{c}\text { Arc } \\
\text { discharge }\end{array}$ & $?$ & $\begin{array}{c}\text { Partial } \\
\text { discharge or } \\
\text { moisture }\end{array}$ \\
\hline 9 & $\begin{array}{l}\text { High energy } \\
\text { discharge }\end{array}$ & $\begin{array}{l}\text { High energy } \\
\text { discharge }\end{array}$ & $\begin{array}{l}\text { High er } \\
\text { disch }\end{array}$ & $\begin{array}{l}\text { Low energy } \\
\text { discharge }\end{array}$ \\
\hline 10 & $\begin{array}{l}\text { High energy } \\
\text { discharge }\end{array}$ & $\begin{array}{l}\text { High energy } \\
\text { discharge }\end{array}$ & $\begin{array}{l}\text { Low energy } \\
\text { discharge }\end{array}$ & $\begin{array}{l}\text { High energy } \\
\text { discharge }\end{array}$ \\
\hline 11 & $\begin{array}{l}\text { Low energy } \\
\text { discharge }\end{array}$ & $?$ & $\begin{array}{l}\text { Low energy } \\
\text { discharge }\end{array}$ & $\begin{array}{c}\text { Low energy } \\
\text { discharge or } \\
\text { moisture }\end{array}$ \\
\hline 12 & $\begin{array}{l}\text { Low energy } \\
\text { discharge } \\
\text { and thermal }\end{array}$ & $\begin{array}{c}\text { Low energy } \\
\text { discharge } \\
\text { and } \\
\text { overheating }\end{array}$ & $\begin{array}{l}\text { Low energy } \\
\text { discharge }\end{array}$ & $\begin{array}{c}\text { Low } \\
\text { temperature } \\
\text { thermal / } \\
\text { temperature } \\
\text { overheat }\end{array}$ \\
\hline 13 & $\begin{array}{c}\text { Low } \\
\text { temperature } \\
\text { thermal }\end{array}$ & $\begin{array}{c}\text { Low } \\
\text { temperature } \\
\text { thermal }\end{array}$ & $\begin{array}{c}\text { Low } \\
\text { temperature } \\
\text { thermal }\end{array}$ & $\begin{array}{c}\text { Low } \\
\text { temperature } \\
\text { thermal }\end{array}$ \\
\hline 14 & $\begin{array}{c}\text { High } \\
\text { temperature } \\
\text { thermal }\end{array}$ & $\begin{array}{l}\text { Higher than } \\
700 \text { thermal } \\
\text { fault }\end{array}$ & $\begin{array}{c}\text { High energy } \\
\text { discharge / } \\
\text { high } \\
\text { temperature } \\
\text { overheating }\end{array}$ & $\begin{array}{l}\text { High energy } \\
\text { discharge / } \\
\text { high } \\
\text { temperature } \\
\text { overheating }\end{array}$ \\
\hline
\end{tabular}

\begin{tabular}{|c|c|c|c|c|}
\hline 15 & $\begin{array}{c}\text { Low } \\
\text { temperature } \\
\text { thermal }\end{array}$ & $\begin{array}{c}\text { Low } \\
\text { temperature } \\
\text { thermal }\end{array}$ & $\begin{array}{c}\text { Low } \\
\text { temperature } \\
\text { thermal }\end{array}$ & $?$ \\
\hline
\end{tabular}

When the ratio method for diagnostic use, for the failure in the ratio range, the correct rate is relatively high, but cannot determine the ratio for the failure is not within the scope of the formation of the Missing.

1)Seen from the statistics, a comprehensive algorithm for low Missing two other single law for the type of fault is divided roughly, the correct rate is higher, but the simplistic division of the type of fault is not conducive to further determine the actual failure.

2)Ratio method cannot determine the effect of a variety of related faults, the diagnosis is often an error occurs.

3)Three-ratio method and neural network algorithms for high energy and low energy discharge discharge capacity is not enough to identify, often misjudge Missing phenomenon.

4)Synthesis algorithm can avoid inadequate threeratio method and neural network algorithm, a more comprehensive diagnosis of the sample, according to the conclusions of the table shows, the higher its diagnostic accuracy.

Due to a variety of methods have advantages and disadvantages can be seen using a combination of methods to obtain higher accuracy, the results of fault diagnosis for better reference value. Therefore, this paper focuses on the opportunities DGA's Intelligent Fault Diagnosis Method has a good combination of practical significance.

\section{Conclusion}

This paper is the study of a comprehensive fault diagnosis method, according to the knowledge base and oil chromatogram troubleshooting cases library established transformer fault diagnosis method for assessing intelligence and neural networks combination of Case-based inference. Through practice tests proved the effectiveness of this integrated approach for latent internal transformer fault diagnosis, avoid misjudgement traditional three-ratio method, the miscarriage of justice or incomplete coding shortcomings, to a certain extent, improve the accuracy of fault diagnosis of transformer rate. But for the sudden failure, this method does not validate in future studies also need to sudden failure of the transformer were analyzed.

\section{Acknowledgement}

This work is in part supported by the National High-tech R\&D Program of China (863 Program) (No.2015AA050204) and Science and Technology Program of State Grid Corporation of China (No.GY7115-045).

\section{References}


1. People's Republic of China National Standard.GB7252-2001.Dissolved gases in transformer oil analysis and judgment guidelines Beijing: China Standard Press, (2002)

2. Zhengrong Wang, Xiaojian Deng. Transformer oil dissolved gas analysis online intelligent diagnostic systems. Power System Engineering[J], 14 (1) : 64 66, (2002)

3. Caixin Sun, Junfeng Guo. Gas analysis in the study of fuzzy clustering multi-mode fault diagnosis method of transformer oil dissolved. China Electrical Engineering $[\mathrm{J}], 21$ (2) : 34 41, (2001)

4. Ferrito Sam J.A Comparative Study of Dissolved Gas Analysis Techniques: The Vacuum Extraction Method Versus the Direct Injection Method. IEEE Trans. On PD, 5 (1) : 220 225, (1990).

5. Inoue $\mathrm{Y}$, Suganuma $\mathrm{K}$, Kamba $\mathrm{M}$, et al. Development of Oil-dissolved Hydrogen Gas Detector for Diagnosis of Transformers. IEEE Trans. On PD, 5 (1) : 226 232, (1990)
6. Changchang Wang, Fuqi Li, Shengyou Gao. Online monitoring and fault diagnosis of electrical equipment[M], 12 (2011)

7. Jianmin Gu.State maintenance of electrical equipment and computer-aided analysis and forecast[J], 2 (21) , 2, (2004)

8. Mitchell S. Lebold, Karl M. Reichard, Daniel Ferullo, David Boylan, Open System Architecture for Condition-based Maintenance: Overview and Training Material.

9. Penn State University / Applied Research Laboratory, The Boeing Company, and Machinery Information Management Open Standards Alliance (MIMOSA), Open System Architecture for Condition-based Maintenance: Primer.

10. Bengtsson M, Clsson E, Funk P, et a1, Technical design of condition based maintenance system - a case study using sound analysis and case-based reasoning. maintenance and reliability conference proceedings of the 8 th Congress, Knoxville, USA, May 2-5, (2004) 